\title{
REVIEW
}

\section{Memory NK cells: why do they reside in the liver?}

\author{
Xiaojun Jiang ${ }^{1}$, Yonglin Chen ${ }^{1}$, Hui Peng ${ }^{2}$ and Zhigang Tian ${ }^{1,2}$
}

Immune memory is the hallmark of adaptive immunity. However, recent studies have shown that natural killer (NK) cells, key components of the innate immune system, also mediate memory responses in mice and humans. Strikingly, memory NK cells were liver-resident in some models, raising the question as to whether the liver is a special organ for the acquisition of NK cell memory. Here, we review the characteristics of NK cell memory by summarizing recent progress and discuss how the liver may generate both the initiation and the recall phase of memory. We propose that the liver may have unique precursors for memory NK cells, which are developmentally distinct from NK cells derived from bone marrow. Cellular \& Molecular Immunology (2013) 10, 196-201; doi:10.1038/cmi.2013.8; published online 8 April 2013

Keywords: immune memory; liver; NK cell

\section{INTRODUCTION}

Memory is one of the most intriguing powers of a human being. An individual learns from iterative processes and records these instances. Memories are spread by conversation and by books or other media; memories also significantly elevate work efficiency and propel society forward. The immune system, much like human society, is highly compartmentalized. Various immune cells work together and regulate each other, maintaining homeostasis of the body and defending against external challenges. Memory is also present in immune cells such as $\mathrm{T}$ and $\mathrm{B}$ cells, which provide more effective protection to the body. ${ }^{1,2}$

Immunological memory was commonly believed to be a hallmark of the adaptive immune system, but recent studies in three different models found that natural killer (NK) cells, components of the innate immune system, ${ }^{3-6}$ also possess features of immunological memory. ${ }^{7-9}$ Dr von Andrian's group, using a contact hypersensitivity (CHS) model, demonstrated that NK cells can mediate intact memory responses in recombination activating gene-2 $\left(\right.$ Rag $\left._{-2^{-/-}}\right)$mice deficient in $\mathrm{T}$ and $\mathrm{B}$ cells. ${ }^{10,11}$ Dr Lanier's group defined antigen-specific memory features of NK cells in a mouse cytomegalovirus (MCMV) infection model, in which they observed quicker and more effective responses after a secondary virus challenge and four phases of NK cell memory similar to that of memory T cells. ${ }^{12}$ Moreover, Dr Yokoyama's group found that NK cells activated by cytokines in vitro showed enhanced cytokine production upon re-stimulation in adoptive transfer recipients, suggestive of non-specific memory features in the NK cells. ${ }^{13}$
The bone marrow (BM) can act as a nest for memory B and T cells ${ }^{14-16}$ and plasma cells. ${ }^{17-19}$ Whether memory NK cells have similar migratory property is an interesting topic. Accumulated data from several animal models, ${ }^{20}$ show that memory NK cells reside in the liver, suggesting that the liver may be an important organ in NK cell memory. In this review, we will give an overview of the discovery of the NK cell memory capacity and discuss the possible mechanisms of NK cell memory, with an emphasis on the liver as a nest for memory NK cells.

\section{THE FINDING OF MEMORY NK CELLS: A HISTORICAL PERSPECTIVE}

As outlined in Table 1, NK cell memory was firstly observed in a hapten-induced CHS model, a classical model for immune memory in which sensitized $\mathrm{CD} 4^{+} \mathrm{T}$ cells were thought to mediate a hypersensitivity response after secondary hapten challenge. However, the CHS response also occurred in Rag2-deficient mice, which lack T and B cells but possess NK cells. As Rag $2^{-/-} \mathrm{Il}_{2 \mathrm{rg}^{-1-}}$ mice lacking all lymphocytes failed to induce a CHS response, and depletion of NK cells in Rag-2deficient mice also abolished the memory response, NK cells were confirmed to mediate $\mathrm{T}$ and $\mathrm{B}$ cell-independent adaptive immunity. Adoptive transfer assays also showed that only hepatic NK cells from sensitized mice could deliver antigen-specific memory to naive mice. Using antibody depletion assays, Thy-1, Ly49C-I and CXCR6 were defined as markers for memory NK cells in the CHS model..$^{9-11,21}$

Studies based on MCMV infection emphasized four phases of NK cell memory. As MCMV m157 glycoprotein can be

\footnotetext{
${ }^{1}$ Hefei National Laboratory for Physical Sciences at Microscale, Hefei, China and ${ }^{2}$ Department of Immunology, School of Life Sciences, University of Science and Technology of China, Hefei, China

Correspondence: Dr ZG Tian, School of Life Sciences, University of Science and Technology of China, 443 Huangshan Road, Hefei 230027, China. E-mail: tzg@ustc.edu.cn
}

Received: 28 January 2013; accepted: 26 February 2013 
Table 1 Characteristics of NK cell memory in different mouse models

\begin{tabular}{lll}
\hline Models & $\begin{array}{l}\text { Antigen- } \\
\text { specific }\end{array}$ & $\begin{array}{l}\text { Liver- } \\
\text { specific }\end{array}$ \\
\hline CHS & Yes & Yes \\
Influenza, VV, VSV and HIV-1 & Yes & Yes \\
MCMV, genital HSV-2 & Yes & No \\
Cytokine-activated (in vitro) & $?$ & No \\
\hline
\end{tabular}

Abbreviations: CHS, contact hypersensitivity; HIV-1, human immunodeficiency virus type 1; MCMV, mouse cytomegalovirus; NK, natural killer; VSV, vesicular stomatitis virus; VV, vaccinia virus.

recognized by the activating Ly49H receptor expressed on NK cells, the chronological response of $\mathrm{Ly} 49 \mathrm{H}^{+} \mathrm{NK}$ cells was investigated. Virus-activated Ly $49 \mathrm{H}^{+} \mathrm{NK}$ cells went through expansion and contraction phases during the first week of MCMV infection. After the contraction phase, functional memory NK cells were retained in the memory phase. When mice were rechallenged with MCMV, the virus-specific memory NK cells entered the recall phase, and quickly responded and showed more protective effects compared with naive NK cells. This research shed light on the common chronological characteristics of the memory response shared by NK and T cells. ${ }^{12}$

Cytokine-activated NK cells also exhibited memory characteristics in mice. Transferred NK cells pre-stimulated with cytokines in vitro were detectable 7-22 days after injection in the recipients. Although the exogenous long-term surviving NK cells in the recipients displayed a phenotype similar to naive NK cells, they responded more robustly when re-stimulated. Although the ex vivo treatments of the NK cells were artificial, this study demonstrates that NK cells can attain intrinsic memory after prior activation. ${ }^{13}$

More recently, memory NK cells have been reported in viral infections such as influenza, vaccinia virus, vesicular stomatitis virus, genital HSV-2 and human immunodeficiency virus type $1{ }^{11,22,23}$ As in the CHS model, only hepatic NK cells, not splenic NK cells, can mount the virus-specific memory response in all of these models except the genital HSV-2 infection model.

NK cell memory has also been observed in humans. Human NK cells pre-activated with cytokine combinations including IL-12, IL-15 and IL-18 show enhanced IFN- $\gamma$ production after re-stimulation. ${ }^{24}$ Another study showed that $\mathrm{NKG}_{2} \mathrm{C}^{+} \mathrm{NK}$ cells from patients infected with cytomegalovirus could expand in vivo in response to recipient cytomegalovirus antigen after transfer. ${ }^{25}$

Although NK cells show features of adaptive immunity, there are distinct differences. The specific interaction between m157 and Ly49H makes MCMV infection a special case for NK cell memory, leading to the possibility that the memory mechanism of $\mathrm{Ly}_{49 \mathrm{H}^{+}} \mathrm{NK}$ cells in MCMV model is different from that in the CHS model, and $\mathrm{Ly} 49 \mathrm{H}$ was not convincing enough to be a surface marker for memory NK cells. It is noteworthy that the memory NK cells in the MCMV model were not organspecific, while the antigen-specific memory NK cells in the other viral models and the CHS model were resident in the liver.

\section{PREREQUISITES FOR NK CELL MEMORY}

The BM is thought to be the main site for NK cell development after birth both in mice and humans. ${ }^{26-28}$ The generation of the NK cell lineage from hematopoietic stem cells occurs in the BM throughout life. CD122 ${ }^{+} \mathrm{NK} 1.1^{-} \mathrm{CD}^{-}$cells are NK cell-committed precursors (NKPs), which give rise to $\mathrm{CD}^{-} \mathrm{NK} 1.1^{+} \mathrm{NK}$ cells after in vitro culture. ${ }^{29,30}$ In the classical NK cell developmental pathway, NK cells arise from BM NKPs, which then go through an immature NK cell stage and finally become mature NK cells. ${ }^{31} \mathrm{NK}$ cell development and function is controlled by a series of elements, including T-bet, E4BP4, IRF2, HMBOX1 and GATA3. ${ }^{32-35}$ NKPs and immature NK cells can also be found in peripheral organs, suggesting that at any stage, NK cells can leave the BM and finish their development at peripheral sites. ${ }^{34,36}$ Maturation of NK cells is accompanied by the expression of a series of activating and inhibitory receptors. ${ }^{37,38}$ The 'missing self' theory proposed that inhibitory receptors on NK cells can recognize self-MHC molecule and transmit inhibitory signals to avoid self-activation and that only NK cells whose inhibitory receptors (the Ly49 family in mice and the KIR family in humans) have been engaged by self MHC can acquire full effector function. ${ }^{39-41}$ The interaction between MHC molecules and inhibitory receptors is called NK cell licensing; however, when and where the 'licensing' occurs is still not clear.

In $\mathrm{T}$ and $\mathrm{B}$ cells, the gene rearrangement of receptors resulting in clones expressing different types of antigen-specific receptors is necessary for memory formation. ${ }^{42,43}$ Specific clones are chosen and proliferate following a secondary antigenic challenge. The basis for NK cell memory seems different because unlike $\mathrm{T}$ and $\mathrm{B}$ cells, NK cells lack the ability to rearrange their receptors. Thus, the mechanism underlying the antigen-specific recognition of NK cells is of great interest. It is possible that several receptors on NK cells work together and are combined to accomplish specific recognition. The MCMV model is a simplified model, as m157 is recognized by Ly49H. ${ }^{12}$ Memory NK cells specific to viruses may simultaneously combine various receptors to recognize distinct antigens.

Memory cells are lymphocyte populations with long-lived and self-renewing properties ${ }^{44-46}$ and are capable of antigenspecific recognition. For decades, NK cells were considered to have a short lifespan and lack the capacity of self-renewal; ${ }^{31}$ however, a recent study found that adoptive transfer of NK cells into lymphopenic hosts resulted in the generation of a longlived NK cell population, which could reside in both lymphoid and non-lymphoid tissues for more than 6 months. ${ }^{47}$ These homeostasis-driven NK cells were able to self-renew and respond strongly upon re-encounter with a virus. Compared to the well-documented requirements for T-cell longevity, the factors determining the homeostatic proliferation and longevity of NK cells are poorly defined. IL-15 plays a key role in the homeostasis and survival of NK cells and in NK cell 
development. ${ }^{48}$ IL-15 signaling can upregulate anti-apoptotic factors such as Bcl-2 and suppress pro-apoptotic factors such as BIM and Noxa in NK cells, thus protecting NK cells from apoptosis. T-cell receptor (TCR) signaling plays a role in the activation of the stem cell transcriptional program in memory $\mathrm{T}$ cells; ${ }^{49}$ however, its effect on NK cell receptors needs further investigation.

\section{POSSIBLE MECHANISMS INVOLVED IN NK CELL MEMORY}

How NK cells gain memory remains unclear. In the MCMV infection model, the recall response to a secondary antigenic challenge by functional memory NK cells has been described. Changes in NK cell numbers were demonstrated, but how the changes occurred is puzzling. ${ }^{12}$ Similar studies were also reported in models of other virus infections, including vaccinia virus. ${ }^{22}$ It is clear that NK cells can respond to antigens, but many gaps remain in understanding the mechanism for antigen recognition, including when and where the recognition happens and what receptors are involved in the process.

Silke Paust and Ulrich $\mathrm{H}$ von Andrian proposed a paradigm for the generation, maintenance and recall of NK cells memory in the CHS model. Peripheral NK cells were primed in the draining lymph nodes by antigen-presenting cells carrying antigens after sensitization. These NK cells recognized the antigen but did not mount a strong response. The sensitized NK cells patrolled the blood system and were selectively localized to the liver using adhesion molecules such as CXCR6. After the same hapten challenge at another site, these memory NK cells quickly departed from liver and were recruited to the location of the secondary challenge. ${ }^{20}$

It is possible that antigen recognition by NK cells happens in the liver. As an important metabolic organ, ${ }^{50,51}$ the liver may degrade chemical haptens. Haptens are carried to the liver by the bloodstream, and hepatic immune cells may react to clear the toxic material. Previous studies in the CHS model demonstrated that hepatic invariant NK T cells released IL-4 as early as 7 min after sensitization and stimulatory lipids accumulated in the mouse liver within $30 \mathrm{~min}$ of sensitization. ${ }^{52}$ We have evidence that after sensitization with FITC, FITC-bound cells could be detected in the liver, especially on hepatocytes and liver monocytes, but not in the spleen. ${ }^{53}$ Therefore, it is possible that, rather than the recruitment of sensitized NK cells to the liver after a local response, antigenic activation of the NK cells occurs in the liver. Moreover, hepatic NK cells express high levels of CD11c, ${ }^{54,55}$ suggesting that they may be capable of antigen presentation.

WHY RESIDE IN THE LIVER: IMMIGRANTS OR NATIVES We noticed that the most significant difference between the MCMV model and other models was that the MCMV-specific memory NK cells were not organ specific, whereas the memory NK cells in other models resided only in the liver. As discussed above, most NK cells in B6 mice express Ly49H, which can specifically recognize MCMV m157, making MCMV infection a special case. Thus, the fact that memory NK cells reside in the liver suggests that hepatic NK cells may be able to recognize certain antigens, which means that the receptor repertoire of hepatic NK cells is different from that of conventional NK cells.

The liver is a solid organ, and immune cells in the liver can be divided into resident cells and passer-by cells. Resident cells either come from other organs or develop in the liver. They exist in a stable state in the hepatic sinusoid and do not spontaneously leave. Passer-by cells go through the liver via the bloodstream like travelers. As reported before, the fetal liver is the main hematopoietic organ during embryogenesis, and the hematopoietic ability of liver is maintained to some extent until adulthood. ${ }^{56,57}$ Thus, the developmental pathway for hepatic lymphocytes may be unique.

The source of the antigen-specific hepatic NK cells is a central issue. Whether memory NK cells in the liver are special immigrants recruited from the periphery or whether they are natives with distinct receptor repertoire should be considered before elucidating the origin of the hepatic memory NK cells (Figure 1). If the memory NK cells are immigrants, the location of where the NK cells acquire memory is worth discussion. Memory NK cells may gain memory in the periphery and then be selectively recruited to the liver, as discussed above. However, the acquisition of the memory capacity may be a process, akin to education, which happens in the liver. 'Multi-talented NK cells', which may have specific receptors, are recruited and acquire the capacity for memory in the liver. If the memory NK cells are natives, there are also two other possibilities. One possibility is that NKPs from the BM are retained in the liver and develop in the liver microenvironment.

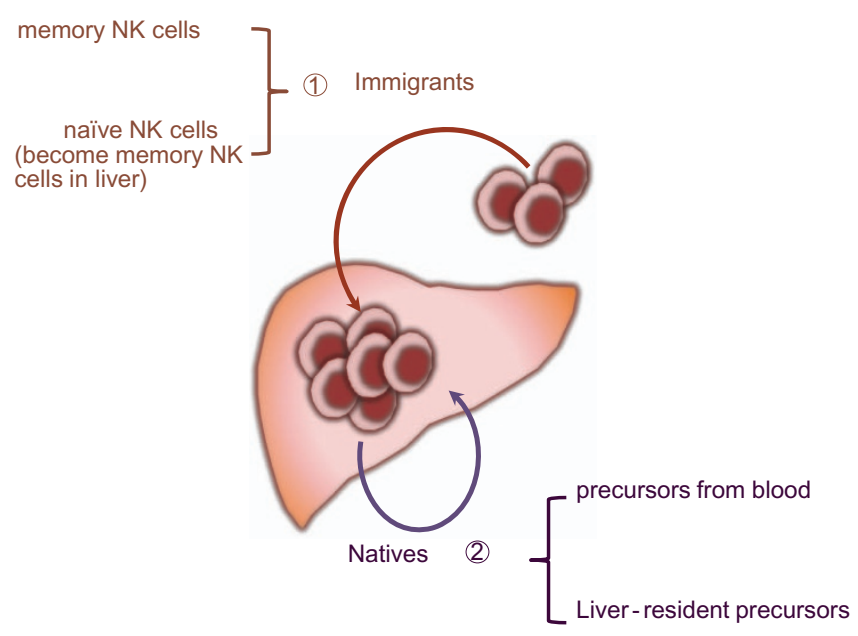

Figure 1 The possible origins of liver-resident memory NK cells. Multiple possible sources for memory NK cells in the liver are proposed. The liver may collect memory NK cells or 'multi-talented naive NK cells' from periphery through blood circulation. 'Multi-talented naive NK cells' preferentially accumulate in the liver during homeostasis or during the sensitization process of the $\mathrm{CHS}$ response, and acquire memory capacity to respond to the antigens. However, possibilities also exist that the 'multi-talented naive NK cells' in the liver originate from either the adult BM HPCs by blood circulation or from fetal liver HPCs in situ. BM, bone marrow; CHS, contact hypersensitivity; HPC, hematopoietic progenitor cell; NK, natural killer. 


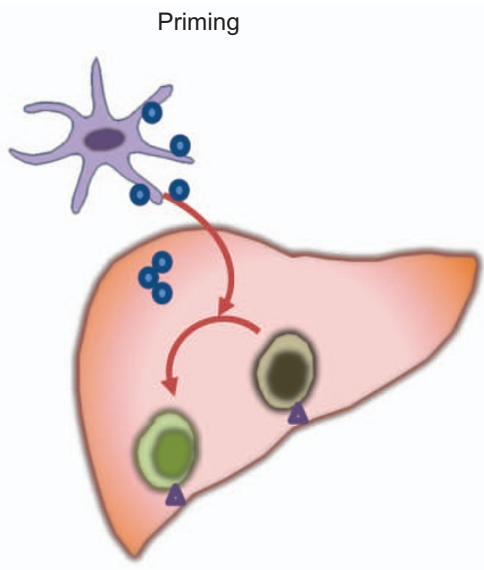

NK cells with memory potency

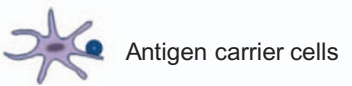

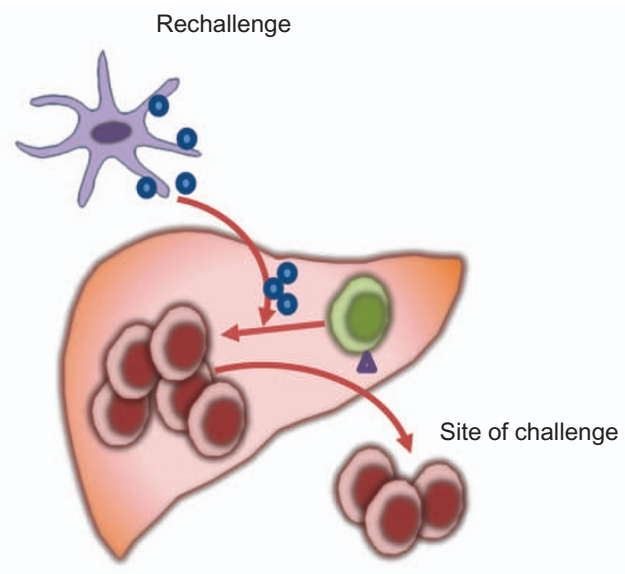

memory NK cells

effector NK cells

- chemokines and adhesion molecules

Figure 2 Working model of the response of liver-resident memory NK cells to peripheral stimulation. In the steady-state, NK cells with memory potential exist in the liver. During the priming phase, antigens enter the liver directly through the bloodstream or are carried by antigen presenting cells. NK cells with memory potential respond to antigens in the liver, proliferate and expand without phenotypic alterations. Upon the challenge with the same hapten at distal sites, the memory NK cells differentiate into effector NK cells in response to the second hapten stimulation, and leave the liver to exert effector functions at the site of challenge. NK, natural killer.

The other possibility is that fetal liver HPCs keep their hematopoietic function to further differentiate into NK cells in the adult liver. ${ }^{58}$

We have confirmed the memory potential of liver-specific DX5 ${ }^{-} \mathrm{CD} 49 \mathrm{a}^{+} \mathrm{NK}$ cells, which are absent in periphery and demonstrated that NK cells in other organs fail to acquire the capacity for memory after sensitization. ${ }^{53}$ Therefore, we favor the idea that memory potential is a unique immunological feature of hepatic NK cells. We also found that liver-specific DX5 ${ }^{-} \mathrm{CD} 49 \mathrm{a}^{+} \mathrm{NK}$ cells were absent in both afferent and efferent blood in the liver under normal condition and during a CHS response. Moreover, NK cells in the peripheral blood and ears during the recall response were mostly $\mathrm{DX} 5^{+}$; therefore, we propose that DX5 ${ }^{-} \mathrm{CD} 49 \mathrm{a}^{+} \mathrm{NK}$ cells sensed antigens in the liver and acquired memory locally. These memory NK cells may be retained in the liver or released at undetectable amounts into the bloodstream to patrol the periphery for antigen rechallenge.

\section{A QUESTION OF TRAVELING: HOW TO RECALL LOCALLY IN RESPONSE TO ANTIGEN}

Memory NK cells reside and persist in the liver after sensitization, a situation analogous to the preferential accumulation of memory T cells in the BM. ${ }^{15,59}$ It has been documented that hematopoietic stem cells in the BM provide the special microenvironment, known as the niche, for recruitment of memory cells. ${ }^{60,61}$ Because hematopoietic stem cells have been demonstrated to be present in the liver, ${ }^{62-64}$ whether a similar 'niche' leading to the residence of memory NK cells exist in the liver needs to be confirmed. In addition, the hematopoietic stem cells in the liver may provide the necessary basis for long-lived memory NK cells.

Memory NK cells also have to function at the local site during an antigen rechallenge. Although we discussed the possible mechanisms involved in NK cell memory in part, how this process occurs is still unclear. The same puzzle also exists in the mechanism of the recall response in adaptive immune responses. Memory T cells preferentially migrate to the BM, and memory $\mathrm{T}$ cells are found in the periphery. ${ }^{65,66}$ Central memory $\mathrm{T}$ cells and effector memory $\mathrm{T}$ cells represent two distinct types of memory $\mathrm{T}$ cells that patrol lymphoid organs and extralymphoid organs, ${ }^{67,68}$ respectively. The BM possibly serves as a renewal pool for the migrating memory cells, thus explaining why $\mathrm{T}$ cells can rapidly respond to a secondary challenge.

If the liver is the nest for memory NK cells, similar to the role of BM for memory $\mathrm{T}$ cells, memory NK cells that patrol the periphery are necessary to initiate a response during antigen restimulation, similar to the situation in T cells. However, memory NK cells with the phenotype of $\mathrm{CD} 49 \mathrm{a}^{+} \mathrm{DX} 5^{-}$were undetected in blood. They seem to be tissue resident and non-migratory. Thus, it is hard to understand how hepatic NK cells sense antigens after a second challenge at another site. ${ }^{53}$ A potential mechanism may be that memory NK cells change their phenotype in the liver after an antigenic challenge to become effector NK cells, and these effector NK cells with a different phenotype depart the liver to exert memory functions (Figure 2).

\section{CONCLUDING REMARKS}

NK cell memory is a striking discovery that overturns previous concepts of innate and adaptive immunity. Though previous 
publications provide strong evidence for NK cell memory in different murine models and in humans, the concrete mechanisms of NK cell memory remain elusive. When and where NK cells recognize antigens, and why memory NK cells are retained in the liver, are questions that need to be solved.

Considering the complexity of the NK cell receptor repertoire, it is possible that an NK cell may gain specific memory of several antigens. In contrast to the selection of TCR-specific $\mathrm{T}$ cells, NK cell memory of antigens seems unclear, and genetically identical NK cells may be endowed with different types of memory depending on the category of antigens they met. An interesting but unanswered question is what would happen if memory NK cells for antigen A encountered antigen B and whether they could remember antigen $B$ and mediate a recall response after a secondary challenge with antigen $\mathrm{B}$.

Whether NK cell receptors will change after specific recognition is another interesting question. Previous studies demonstrated that TCR structures changed after contact with the certain antigens during both negative and positive selection in the thymus and that the alterations determined the later fates of the T cells. ${ }^{69} \mathrm{NK}$ cell engagement with antigen may also be meaningful in NK cells after development in the BM. The liver seems to be a possible local site for this reprogramming. A unique cytokine microenvironment in the liver may supply a solid basis for this reprogramming. Further studies on NK cell memory are of great importance.

NK cell memory and T cell memory share several common characteristics, such as similar phases for memory formation and a more efficient response to antigenic rechallenge. However, $\mathrm{T}$ cells greatly outnumber NK cells. The highly diversity of TCR receptors and strong proliferative capacity of $\mathrm{T}$ cells make us curious about whether NK cell memory can take place in individuals with an intact adaptive immune system including $\mathrm{T}$ and $\mathrm{B}$ cells. Earlier confirmation of NK cell memory was performed in Rag $2^{-/-}$mice deficient in $\mathrm{T}$ and $\mathrm{B}$ cells, and similar phenomena were also later observed in normal mice, suggesting that NK cell memory naturally exists. Long persistence of NK cells were found in hantavirus infected patients, ${ }^{70}$ and memory-like NK cells were reported in virus infections as well, ${ }^{23}$ but more evidence for memory NK cells in humans is needed to provide new vaccination strategies targeting innate immune therapy. As NK cell expansion in vitro has been realized ${ }^{71}$ in diseases with abnormal $\mathrm{T}$ and $\mathrm{B}$ cell functions, pre-stimulated NK cells may have promising applications.

1 Ahmed R, Gray D. Immunological memory and protective immunity: understanding their relation. Science 1996; 272: 54-60.

2 Steinman L. Lessons learned at the intersection of immunology and neuroscience. J Clin Invest 2012; 122: 1146-1148.

3 Seaman WE, Blackman MA, Gindhart TD, Roubinian JR, Loeb JM, Talal N. beta-Estradiol reduces natural killer cells in mice. J Immunol 1978; 121: 2193-2198.

4 Kumar V, Ben-Ezra J, Bennett M, Sonnenfeld G. Natural killer cells in mice treated with 89strontium: normal target-binding cell numbers but inability to kill even after interferon administration. J Immunol 1979; 123: 1832-1838.

5 Quinnan GV, Manischewitz JE. The role of natural killer cells and antibody-dependent cell-mediated cytotoxicity during murine cytomegalovirus infection. J Exp Med 1979; 150: 1549-1554.

6 Lanier LL, Phillips JH, Hackett J Jr, Tutt M, Kumar V. Natural killer cells: definition of a cell type rather than a function. J Immunol 1986; 137: 2735-2739.

7 Vivier E, Raulet DH, Moretta A, Caligiuri MA, Zitvogel L, Lanier LL et al. Innate or adaptive immunity? The example of natural killer cells. Science; 331: 44-49.

8 Biron CA. More things in heaven and earth: defining innate and adaptive immunity. Nat Immunol 2010; 11: 1080-1082.

9 Paust S, Senman B, von Andrian UH. Adaptive immune responses mediated by natural killer cells. Immunol Rev 2010; 235: 286-296.

10 O'Leary JG, Goodarzi M, Drayton DL, von Andrian UH. T cell- and B cell-independent adaptive immunity mediated by natural killer cells. Nat Immunol 2006; 7: 507-516.

11 Paust S, Gill HS, Wang BZ, Flynn MP, Moseman EA, Senman B et al. Critical role for the chemokine receptor CXCR6 in NK cell-mediated antigen-specific memory of haptens and viruses. Nat Immunol 2010; 11: 1127-1135.

12 Sun JC, Beilke JN, Lanier LL. Adaptive immune features of natural killer cells. Nature 2009; 457: 557-561.

13 Cooper MA, Elliott JM, Keyel PA, Yang L, Carrero JA, Yokoyama WM. Cytokine-induced memory-like natural killer cells. Proc Natl Acad Sci USA 2009; 106: 1915-1919.

14 Di Rosa F, Pabst R. The bone marrow: a nest for migratory memory $T$ cells. Trends Immunol 2005; 26: 360-366.

15 Tokoyoda K, Zehentmeier S, Hegazy AN, Albrecht I, Grun JR, Lohning $\mathrm{M}$ et al. Professional memory $\mathrm{CD}^{+}{ }^{+} \mathrm{T}$ lymphocytes preferentially reside and rest in the bone marrow. Immunity 2009; 30: 721-730.

16 Zhao E, Xu H, Wang L, Kryczek I, Wu K, Hu Y et al. Bone marrow and the control of immunity. Cell Mol Immunol 2012; 9: 11-19.

17 Manz RA, Thiel A, Radbruch A. Lifetime of plasma cells in the bone marrow. Nature 1997; 388: 133-134.

18 McMillan R, Longmire RL, Yelenosky R, Lang JE, Heath V, Craddock CG. Immunoglobulin synthesis by human lymphoid tissues: normal bone marrow as a major site of IgG production. J Immunol 1972; 109: 1386-1394.

19 Zuidscherwoude $M$, van Spriel $A B$. The origin of IgE memory and plasma cells. Cell Mol Immunol 2012; 9: 373-374.

20 Paust S, von Andrian UH. Natural killer cell memory. Nat Immunol 2011; 12: 500-508.

21 Rouzaire $\mathrm{P}$, Luci C, Blasco E, Bienvenu J, Walzer T, Nicolas JF et al. Natural killer cells and T cells induce different types of skin reactions during recall responses to haptens. Eur J Immunol 2012; 42: 80-88.

22 Gillard GO, Bivas-Benita M, Hovav AH, Grandpre LE, Panas MW, Seaman MS et al. Thy ${ }^{+}$NK [corrected] cells from vaccinia virusprimed mice confer protection against vaccinia virus challenge in the absence of adaptive lymphocytes. PLoS Pathog 2011; 7: e1002141.

23 Abdul-Careem MF, Lee AJ, Pek EA, Gill N, Gillgrass AE, Chew MV et al. Genital HSV-2 infection induces short-term NK cell memory. PLOS ONE 2012; 7: e32821.

24 Romee R, Schneider SE, Leong JW, Chase JM, Keppel CR, Sullivan $\mathrm{RP}$ et al. Cytokine activation induces human memory-like NK cells. Blood 2012; 120: 4751-4760.

25 Foley B, Cooley S, Verneris MR, Curtsinger J, Luo X, Waller EK et al. Human cytomegalovirus (CMV)-induced memory-like $\mathrm{NKG}_{2} \mathrm{C}^{+} \mathrm{NK}$ cells are transplantable and expand in vivo in response to recipient CMV antigen. J Immunol 2012; 189: 5082-5088.

26 Kim S, lizuka K, Kang HS, Dokun A, French AR, Greco S et al. In vivo developmental stages in murine natural killer cell maturation. Nat Immunol 2002; 3: 523-528.

27 Galy A, Travis M, Cen D, Chen B. Human T, B, natural killer, and dendritic cells arise from a common bone marrow progenitor cell subset. Immunity 1995; 3: 459-473.

28 Carotta S, Pang SH, Nutt SL, Belz GT. Identification of the earliest NK-cell precursor in the mouse BM. Blood 2011; 117: 5449-5452. 
29 Rosmaraki EE, Douagi I, Roth C, Colucci F, Cumano A, Di Santo JP. Identification of committed NK cell progenitors in adult murine bone marrow. Eur J Immunol 2001; 31: 1900-1909.

30 Fathman JW, Bhattacharya D, Inlay MA, Seita J, Karsunky H, Weissman IL. Identification of the earliest natural killer cell-committed progenitor in murine bone marrow. Blood 2011; 118: 5439-5447.

31 Yokoyama WM, Kim S, French AR. The dynamic life of natural killer cells. Annu Rev Immunol 2004; 22: 405-429.

$32 \mathrm{Wu}$ L, Zhang $\mathrm{C}$, Zhang J. HMBOX1 negatively regulates NK cell functions by suppressing the NKG2D/DAP10 signaling pathway. Cell Mol Immunol 2011; 8: 433-440.

33 Glimcher LH, Townsend MJ, Sullivan BM, Lord GM. Recent developments in the transcriptional regulation of cytolytic effector cells. Nat Rev Immunol 2004; 4: 900-911.

34 Di Santo JP. Natural killer cell developmental pathways: a question of balance. Annu Rev Immunol 2006; 24: 257-286.

35 Male V, Nisoli I, Gascoyne DM, Brady HJ. E4BP4: an unexpected player in the immune response. Trends Immuno/ 2012; 33: 98-102.

36 Huntington ND, Tabarias H, Fairfax K, Brady J, Hayakawa Y, Degli-Esposti MA et al. NK cell maturation and peripheral homeostasis is associated with KLRG1 up-regulation. J Immunol 2007; 178: 4764-4770.

37 Chiossone L, Chaix J, Fuseri N, Roth C, Vivier E, Walzer T. Maturation of mouse NK cells is a 4-stage developmental program. Blood 2009 113: 5488-5496.

38 Hayakawa Y, Smyth MJ. CD27 dissects mature NK cells into two subsets with distinct responsiveness and migratory capacity. $\mathrm{J}$ Immunol 2006; 176: 1517-1524.

39 Ljunggren HG, Karre K. In search of the 'missing self': MHC molecules and NK cell recognition. Immunol Today 1990; 11: 237-244.

40 Kim S, Poursine-Laurent J, Truscott SM, Lybarger L, Song YJ, Yang L et al. Licensing of natural killer cells by host major histocompatibility complex class I molecules. Nature 2005; 436: 709-713.

41 Anfossi N, Andre P, Guia S, Falk CS, Roetynck S, Stewart CA et al. Human NK cell education by inhibitory receptors for MHC class I. Immunity 2006; 25: 331-342.

42 Polic B, Kunkel D, Scheffold A, Rajewsky K. How alpha beta T cells deal with induced TCR alpha ablation. Proc Natl Acad Sci USA 2001; 98: 8744-8749.

43 Maruyama M, Lam KP, Rajewsky K. Memory B-cell persistence is independent of persisting immunizing antigen. Nature 2000; 407 636-642.

44 Manz RA, Lohning M, Cassese G, Thiel A, Radbruch A. Survival of long-lived plasma cells is independent of antigen. Int Immunol 1998; 10: 1703-1711.

45 Schluns KS, Lefrancois L. Cytokine control of memory T-cell development and survival. Nat Rev Immunol 2003; 3: 269-279.

46 Lugli E, Dominguez MH, Gattinoni L, Chattopadhyay PK, Bolton DL, Song $\mathrm{K}$ et al. Superior T memory stem cell persistence supports longlived T cell memory. J Clin Invest 2013; 12: 6-8.

47 Sun JC, Madera S, Bezman NA, Beilke JN, Kaplan MH, Lanier LL. Proinflammatory cytokine signaling required for the generation of natural killer cell memory. J Exp Med 2012; 209: 947-954.

48 Ranson T, Vosshenrich CA, Corcuff E, Richard O, Muller W, Di Santo JP. IL-15 is an essential mediator of peripheral NK-cell homeostasis. Blood 2003; 101: 4887-4893.

49 Wang X, Werneck MB, Wilson BG, Kim HJ, Kluk MJ, Thom CS et al. TCR-dependent transformation of mature memory phenotype T cells in mice. J Clin Invest 2011; 121: 3834-3845.

50 Gao B, Jeong WI, Tian Z. Liver: an organ with predominant innate immunity. Hepatology 2008; 47: 729-736.

51 Protzer U, Maini MK, Knolle PA. Living in the liver: hepatic infections. Nat Rev Immunol 2012; 12: 201-213.

52 Dey N, Szczepanik M, Lau K, Majewska-Szczepanik M, Askenase PW. Stimulatory lipids accumulate in the mouse liver within $30 \mathrm{~min}$ of contact sensitization to facilitate the activation of Naive iNKT cells in a CD1d-dependent fashion. Scand J Immunol 2011; 74: 52-61.

53 Peng H, Jiang X, Chen Y, Dorothy KS, Wei H, Gao X et al. Liver-resident NK cells confer adaptive immunity in skin-contact inflammation. J Clin Invest 2013; 123. (In press)

54 Wu X, Chen Y, Wei H, Sun R, Tian Z. Development of murine hepatic NK cells during ontogeny: comparison with spleen NK cells. Clin Dev Immunol 2012; 2012: 759765.

55 Burt BM, Plitas G, Stableford JA, Nguyen HM, Bamboat ZM, Pillarisetty VG et al. CD11c identifies a subset of murine liver natural killer cells that responds to adenoviral hepatitis. J Leukoc Biol 2008; 84: 1039-1046.

56 Costa G, Kouskoff V, Lacaud G. Origin of blood cells and HSC production in the embryo. Trends Immunol 2012; 33: 215-223.

57 Schulz C, Gomez Perdiguero E, Chorro L, Szabo-Rogers H, Cagnard N, Kierdorf $\mathrm{K}$ et al. A lineage of myeloid cells independent of Myb and hematopoietic stem cells. Science 2012; 336: 86-90.

58 Jiang $X$, Chen Y, Peng H, Tian Z. Single line or parallel lines: NK cell differentiation driven by T-bet and Eomes. Cell Mol Immunol2012; 9 . 193-194.

59 Mazo IB, Honczarenko M, Leung H, Cavanagh LL, Bonasio R, Weninger $\mathrm{W}$ et al. Bone marrow is a major reservoir and site of recruitment for central memory $\mathrm{CD}^{+}{ }^{+} \mathrm{T}$ cells. Immunity 2005; 22: 259-270.

60 Tokoyoda K, Hauser AE, Nakayama T, Radbruch A. Organization of immunological memory by bone marrow stroma. Nat Rev Immunol 2010; 10: 193-200.

61 Tokoyoda K, Zehentmeier S, Chang HD, Radbruch A. Organization and maintenance of immunological memory by stroma niches. Eur $J$ Immunol 2009; 39: 2095-2099.

62 Taniguchi H, Toyoshima T, Fukao K, Nakauchi H. Presence of hematopoietic stem cells in the adult liver. Nat Med 1996; 2: 198203.

63 Kotton DN, Fabian AJ, Mulligan RC. A novel stem-cell population in adult liver with potent hematopoietic-reconstitution activity. Blood 2005; 106: 1574-1580.

64 Wang XQ, Lo CM, Chen L, Cheung CK, Yang ZF, Chen YX et al. Hematopoietic chimerism in liver transplantation patients and hematopoietic stem/progenitor cells in adult human liver. Hepatology 2012; 56: 1557-1566.

65 Mueller SN, Gebhardt T, Carbone FR, Heath WR. Memory T cell subsets, migration patterns, and tissue residence. Annu Rev Immunol 2012; in press.

66 Reinhardt RL, Khoruts A, Merica R, Zell T, Jenkins MK. Visualizing the generation of memory CD4 T cells in the whole body. Nature 2001; 410: 101-105.

67 Sallusto F, Lenig D, Forster R, Lipp M, Lanzavecchia A. Two subsets of memory $T$ lymphocytes with distinct homing potentials and effector functions. Nature 1999; 401: 708-712.

68 Masopust D, Vezys V, Marzo AL, Lefrancois L. Preferential localization of effector memory cells in nonlymphoid tissue. Science 2001; 291: 2413-2417.

69 Yin L, Huseby E, Scott-Browne J, Rubtsova K, Pinilla C, Crawford F et al. A single $T$ cell receptor bound to major histocompatibility complex class I and class II glycoproteins reveals switchable TCR conformers. Immunity 2011; 35: 23-33.

70 Bjorkstrom NK, Lindgren T, Stoltz M, Fauriat C, Braun M, Evander M et al. Rapid expansion and long-term persistence of elevated NK cell numbers in humans infected with hantavirus. J Exp Med 2011; 208: 13-21.

71 Luevano M, Madrigal A, Saudemont A. Generation of natural killer cells from hematopoietic stem cells in vitro for immunotherapy. Cell Mol Immunol 2012; 9: 310-320. 